\title{
Integrating Constraint-Based CAD into an Introductory Engineering Graphics Course: Activities and Grading Strategies
}

\author{
Ted J. Branoff, Eric N. Wiebe, and Nathan W. Hartman \\ NC State University, Raleigh, NC
}

\begin{abstract}
Many engineering and technical graphics educators have been revising their curricula over the last several years to incorporate more constraint-based modeling into their introductory courses. Even though there has been some disagreement over what topics should be included in these courses, there seems to be agreement that students need to use this powerful tool to prepare them for industry. With this type of software comes some interesting challenges for faculty: What classroom topics are no longer necessary or important in a constraint-based CAD environment?; What classroom topics are critical to cover in a constraint-based CAD environment?; What types of activities will allow students to realize the full power of the software?; and How should these activities be evaluated? This paper will address how engineering and technical graphics faculty have been coping with the change to constraint-based programs by describing changes in curricula and possible classroom activities that can be used to take advantage of the functionality of the software. Grading strategies for constraint-based CAD activities will also be outlined.
\end{abstract}

\section{Introduction}

Engineering and technical graphics curricula have mainly been focused on documentation practices over the last 50 years. Emphasis has been placed on proper selection and placement of views, dimensioning standards and technique, descriptive geometry, and the ability to visualize objects when given multiview drawings. Within the last 15 years, 3D modeling programs have provided those involved with engineering design new tools with which to work as well as a different way of looking at engineering design. The new generation of software, specifically constraint-based CAD, has shifted the emphasis from documentation to correct part geometry and design intent. Previously, introductory engineering graphics courses included topics such as lettering, correct use of instruments, geometric constructions, multiview and pictorial drawing, sectional views, auxiliary views, dimensioning, and manufacturing processes ${ }^{1}$. These topics may have been successful in the past, but they likely will not prepare students for the current market. The use of geometry orientation and documentation only are no longer sufficient to evaluate how a student will perform with sophisticated CAD tools ${ }^{2}$. Students have to be able to do more than just create static models and drawings extracted from the models ${ }^{3}$. With the current types of tools and software available, industry is looking for individuals who can move data throughout the design process, collaborate online with customers, suppliers and coworkers, identify and fix problems with 3D geometry, use powerful knowledge-based systems to design complex assemblies, and be flexible enough to do design and development work ${ }^{4}$.

\section{Activities}

Many activities can be developed that allow students to realize the full power of constraint-based CAD software. Educators should resist the temptation to only focus on having students create 
static models of parts in order to extract multiview drawings. Concentrating only on static modeling activities will not allow students to experience the full potential of the software. By planning carefully, educators can develop activities such as engineering change notices, reverse engineering exercises, modeling parts from catalogs, and design problems that give students a real appreciation for the power of constraint-based modelers.

\section{Engineering Change Notice}

One type of activity that introduces students to the capabilities of constraint-based CAD software is the engineering change notice (ECN). Instructors can select a single part to be changed in order to demonstrate the importance of a particular geometric relation (such as symmetry or tangency) or to examine ways to break or redefine constraints. For example, an ECN may be set up so students are first required to model the STOP BASE (Figure 1). The instructor may want to emphasize the importance of the tangent relation between the arc and the vertical line in the initial sketch (Figure 2). The student then might be asked to modify the width of the part by changing the 1.760 dimension to 2.500 . The purpose of this step is to verify the tangent constraint between the arc and the line. The final step in the ECN might be to edit the initial sketch by breaking the tangent constraint (Figure 3).

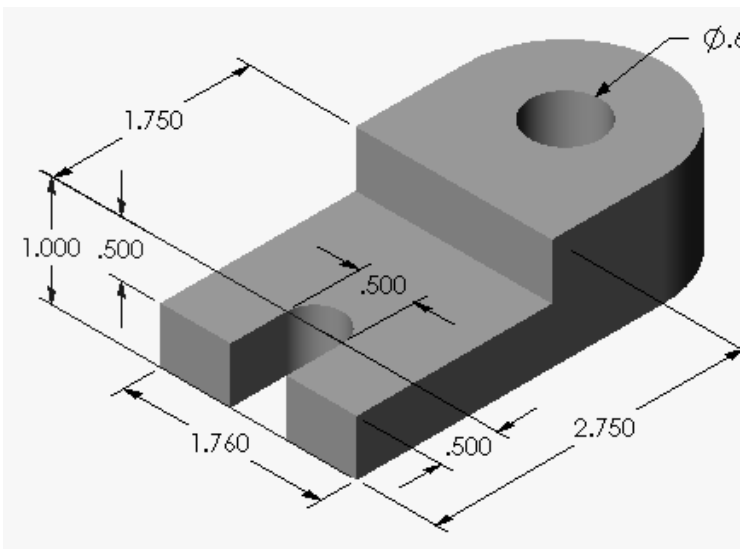

Figure 1. STOP BASE.

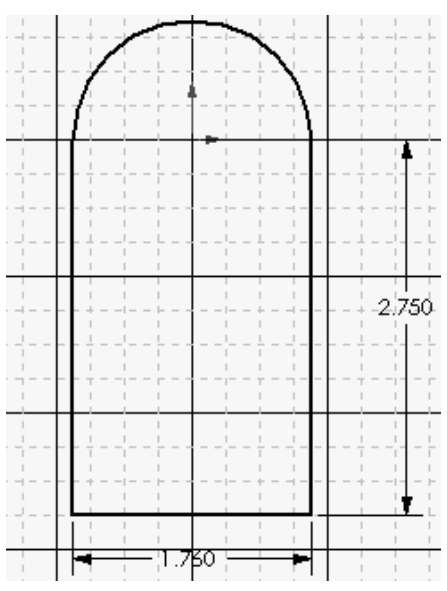

Figure 2. First Sketch for STOP BASE.

Proceedings of the 2003 American Society for Engineering Education Annual Conference \& Exposition. Copyright 2003, American Society for Engineering Education 


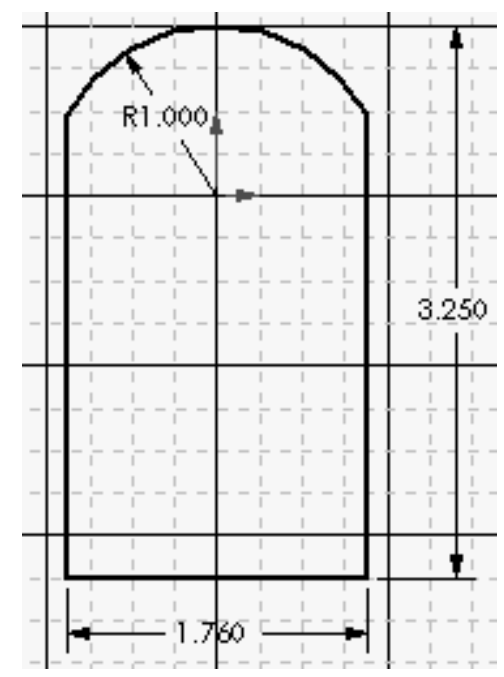

Figure 3. Final Modification of the STOP BASE.

\section{Reverse Engineering}

Reverse engineering activities can be very useful when introducing students to constraint-based $\mathrm{CAD}$ tools. Instructors can provide students with parts to reverse engineer or let students select their own objects. By providing students with objects, instructors can ensure students work with particular types of constraints. Figure 4 shows an example of a hexagon head nut where students must create a regular polygon. Most modelers have built-in routines for creating regular polygons, but instructors might have students explore other methods for fully defining the geometry with additional constraints. When students select their own projects, instructors have to be open to working with all types of constraints and modeling strategies. Figures 5, 6, and 7 illustrate examples of student-selected projects where more sophisticated modeling procedures are required.
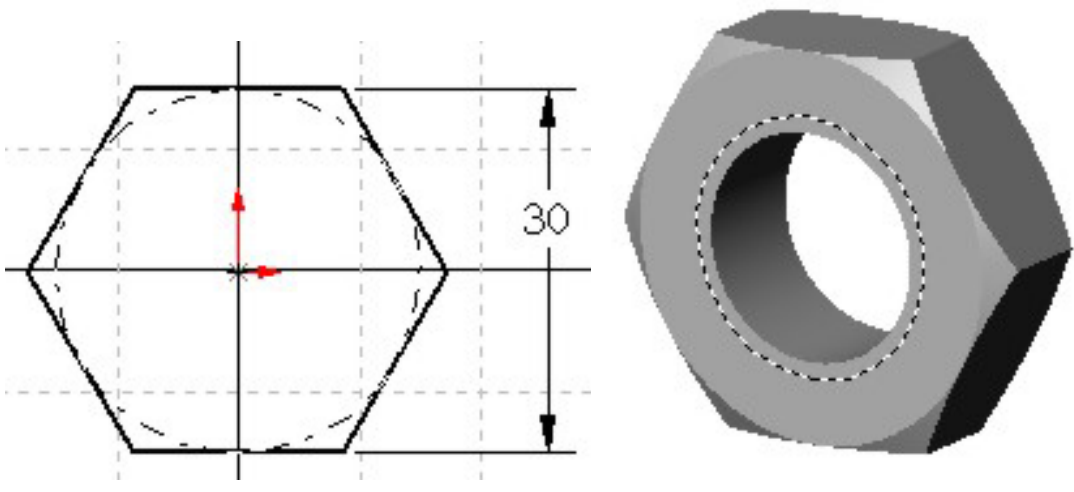

Figure 4. Reverse Engineering a Hexagon Nut. 


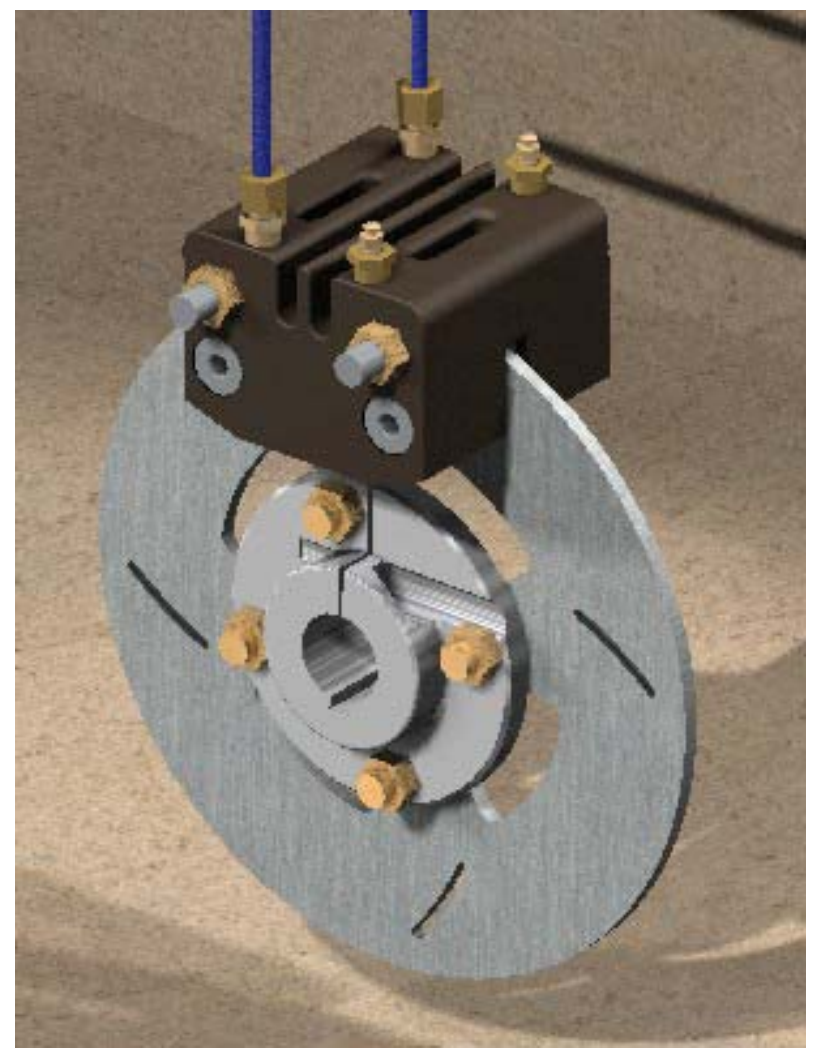

Figure 5. Reverse Engineering of a Brake Assembly.

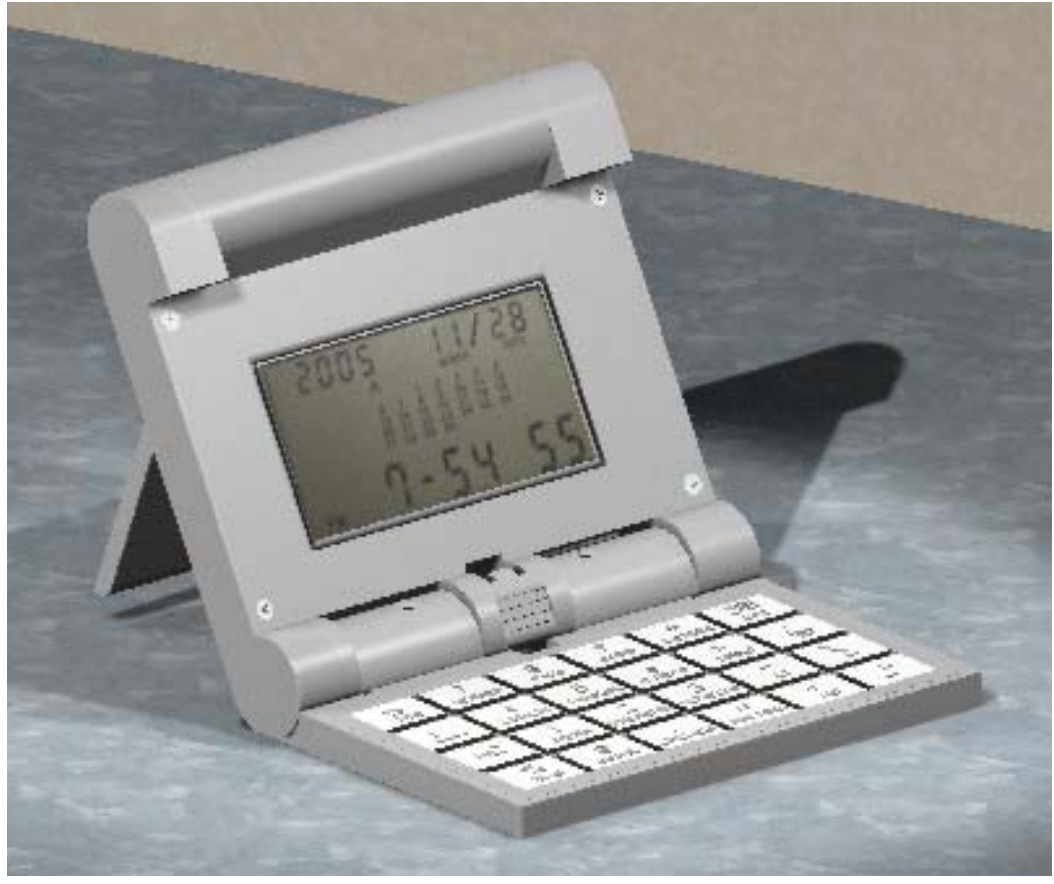

Figure 6. Reverse Engineering of an Electronic Clock.

Proceedings of the 2003 American Society for Engineering Education Annual Conference \& Exposition. Copyright 2003, American Society for Engineering Education 


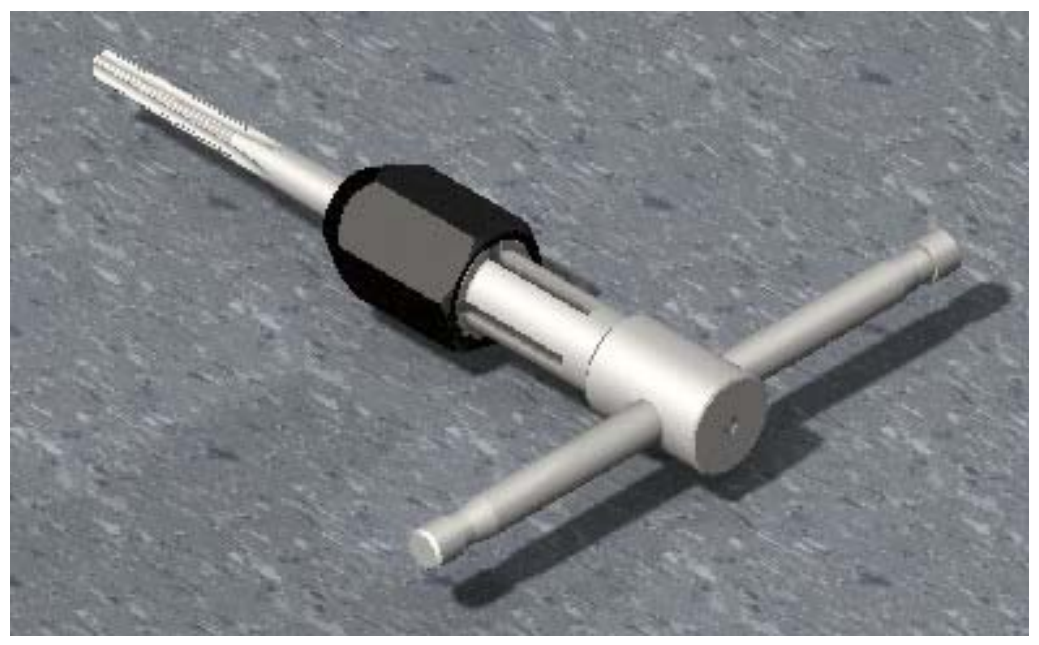

Figure 7. Reverse Engineering of a Thread Tap.

Modeling Parts from Standards Catalogs

Modeling parts from standard catalogs is an excellent method for demonstrating how constraintbased CAD tools work. Most constraint-based CAD programs have some type of function that allows the user to produce multiple parts that share the same geometry. Figure 8 illustrates multiple configurations of a bearing where only the dimensions were modified. The part geometry remained the same for each configuration.
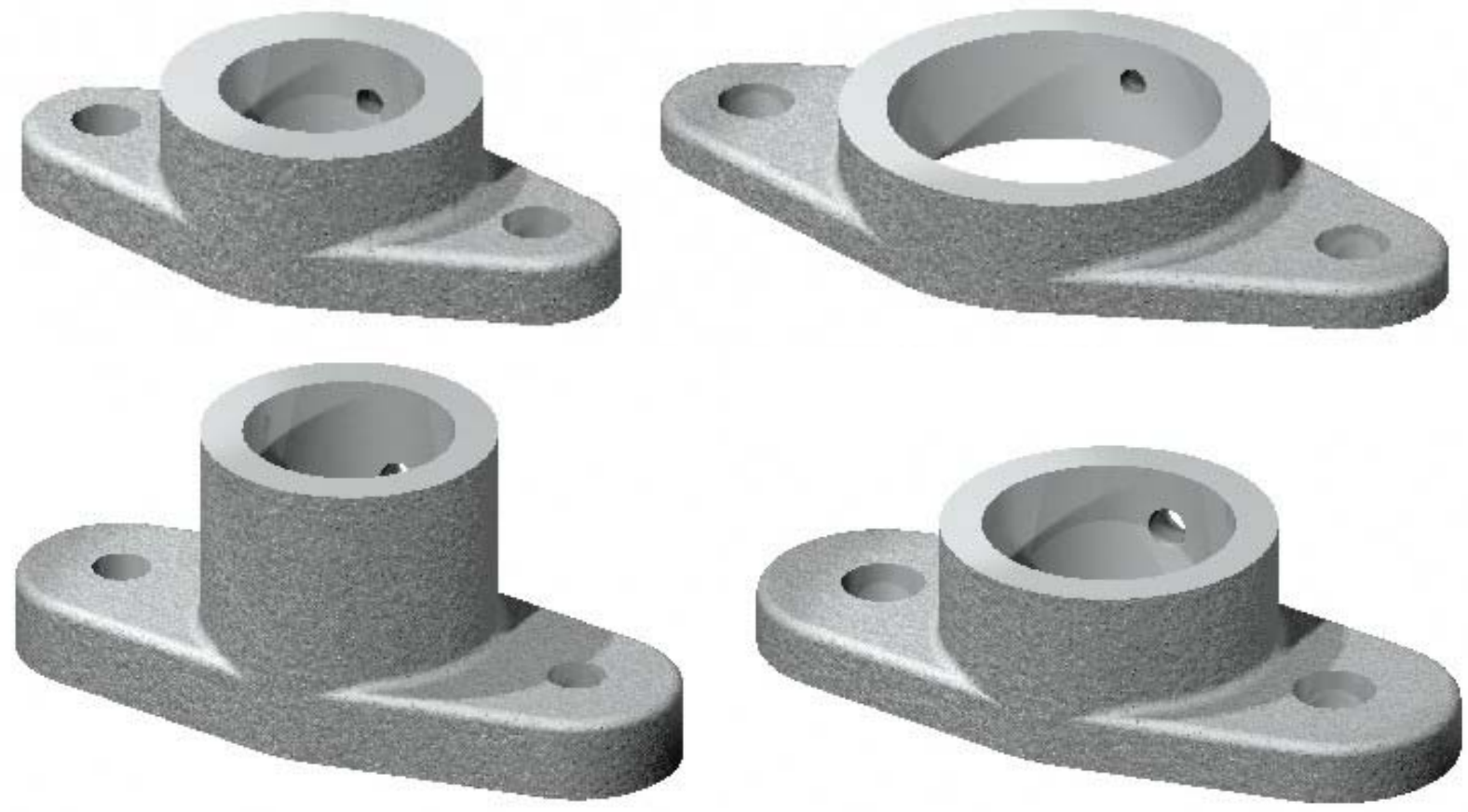

Figure 8. Multiple Configurations of a BEARING.

Proceedings of the 2003 American Society for Engineering Education Annual Conference \& Exposition. Copyright 2003, American Society for Engineering Education 


\section{Design Problems}

Design problems can also help students realize the potential of constraint-based CAD. Educators can create problems that require students to use certain functions in the software in order to solve the design problem. For example, if several iterations of a design are required, a student might be required to use design tables to show multiple solutions (see Figure 8). Other examples include using sweeps and lofts to create irregular surfaces (Figures $9 \& 10$ ).

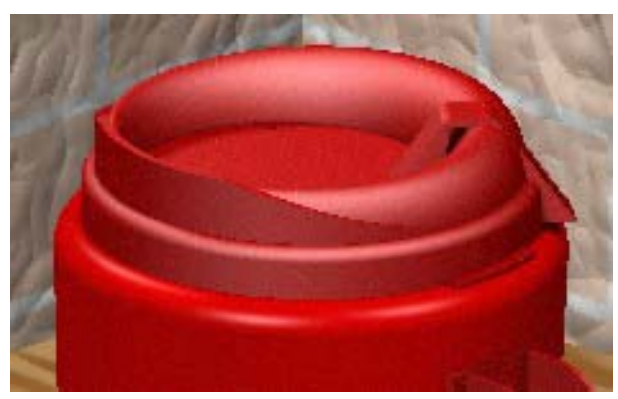

Figure 9. Using a Sweep to Create the Lid on a Travel Mug.
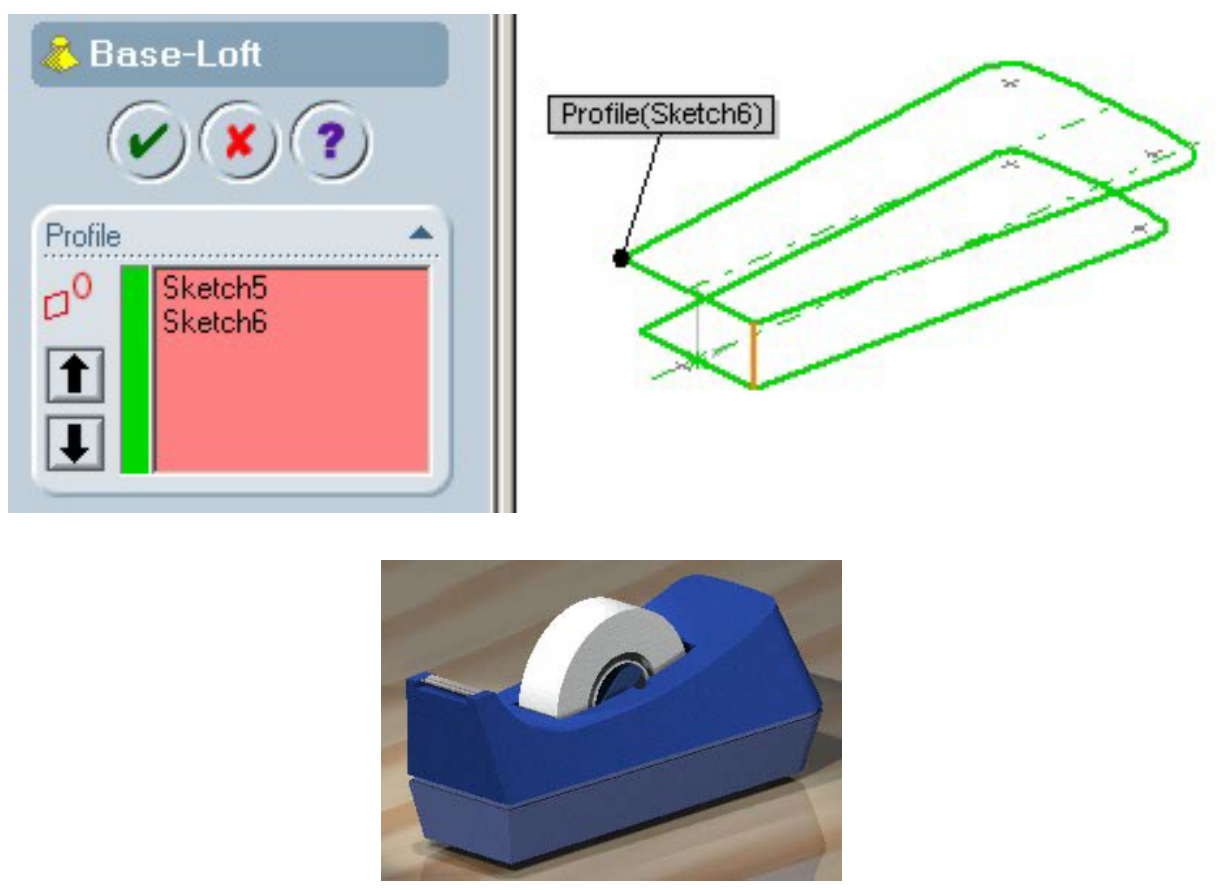

Figure 10. Using a Loft to Create the Base of a Tape Dispenser.

Instructors may also put together projects that utilize combinations of the previous projects (see Figure 11). The following is an example description from a group design project: 
You are members of a design team responsible for coming up with new and exciting $L E G O^{\mathrm{TM}}$ designs. Your first responsibility is to become familiar with standard LEGO ${ }^{\mathrm{TM}}$ pieces by putting together an existing model, creating technical sketches of several pieces (including dimensions), discussing standards for dimensions with your group, and modeling several pieces in the CAD software. As a group you will assemble the pieces in the software per the existing design. The final step of the project is to come up with at least 4 modifications of the existing design. Each modification must include at least one new piece designed by the group. The group will then create four new assemblies incorporating the new pieces.

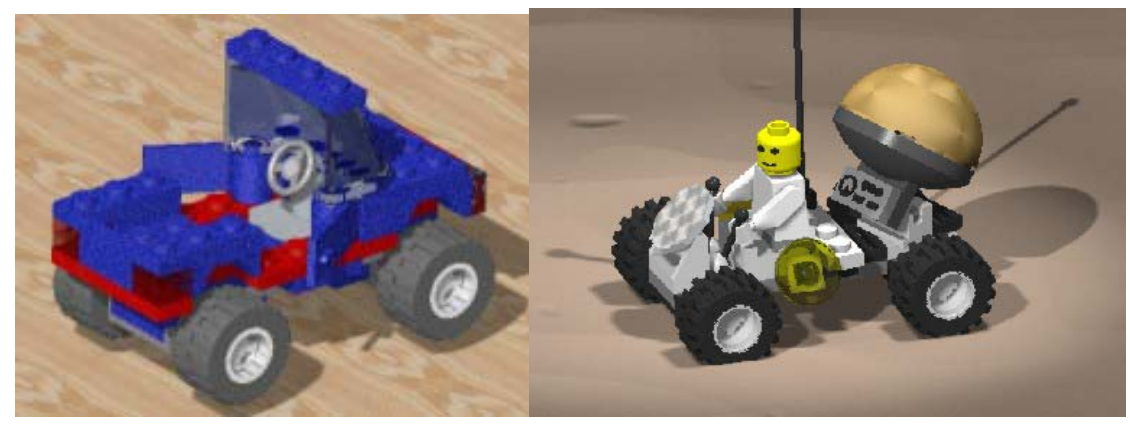

Figure 11. LEGO ${ }^{\mathrm{TM}}$ Project Examples.

\section{Evaluating Assignments}

One of the biggest adjustments educators must make when changing to a constraint-based CAD tool has to do with evaluating assignments. Examining print-outs of solid models or drawings is no longer sufficient to determine the correctness of geometry. A student may create what looks like a line tangent to an arc (see Figure 2), but the model is not correct if the student does not apply the tangent relation between the two entities. In order to effectively evaluate a student's work, the instructor must open the CAD file and examine each feature (Figure 12). This can be a time consuming task, especially when some engineering graphics courses contain hundreds of students. It may be necessary to prioritize the objectives of an assignment and only evaluate the key features of a model ${ }^{5}$. 


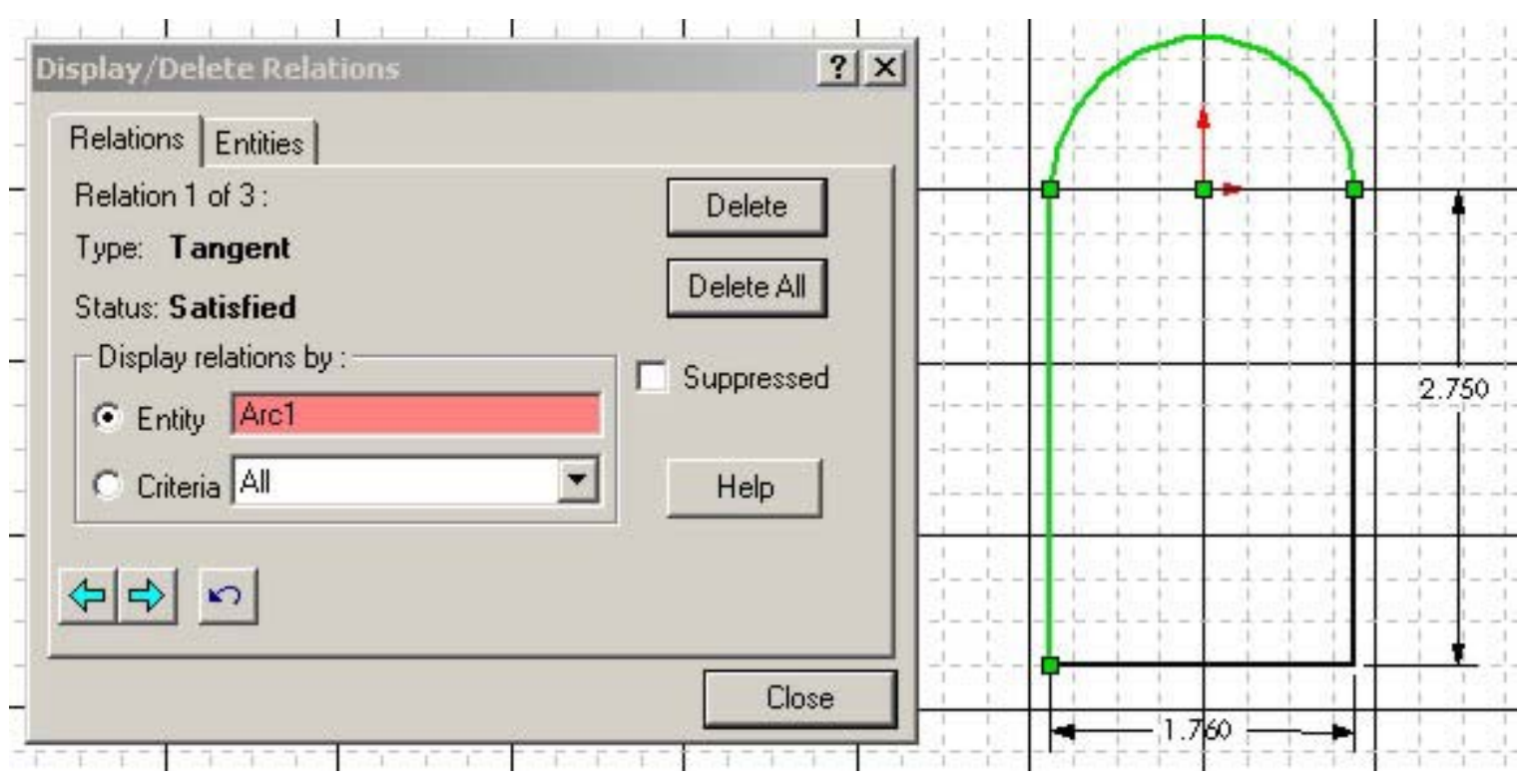

Figure 12. Examine the CAD File to Determine Tangency.

Another critical aspect to consider when designing activities is to develop clear objectives stating how the students will be evaluated. This is good pedagogy since the student knows what is expected and the instructor is evaluating the assignment based on those objectives ${ }^{6}$. The objectives for simple modeling assignments (see Figure 13) might read as follows:

By the end of the assignment, each person should be able to:

1. select the correct template file (1 point).

2. construct the model in the correct orientation (1 point).

3. add the correct relations to each sketch in the model (1 point).

4. add the correct dimensions to each sketch in the model (1 point).

5. include all required features (1 point).

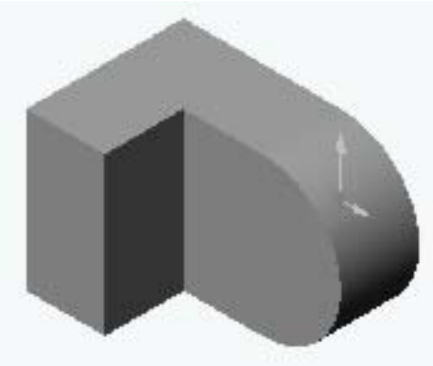

Figure 13. Simple Model.

For smaller class sizes, instructors may put together written comments regarding a student's assignment and then give that person an opportunity to make corrections to the model and resubmit it. An example of a written comment might be:

Proceedings of the 2003 American Society for Engineering Education Annual Conference \& Exposition. Copyright 2003, American Society for Engineering Education 
Cut-Extrude1 sketch is overconstrained. Eliminate concentric relation between the lower circle and the large arc. Choose the Through-All option for holes you intend to go all the way through the part.

Resubmitting homework assignments may become problematic for instructors with large numbers of students. In these cases it is critical that the objectives of the assignments be clearly stated and that the instructor evaluates the assignments based on those objectives.

\section{Conclusion}

The tools used in engineering design continue to become more sophisticated and powerful. One of those tools, constraint-based CAD, puts the 3D database at the center of the concurrent engineering design process. Within this environment, the 3D model is the driving force behind all engineering information. It is critical that our students know how to use this tool and use it correctly. In order for this to happen, engineering graphics educators will have to break away from traditional methods of instruction and design new activities that introduce students to the real power of constraint-based CAD tools. In addition, examining print-outs will no longer be the only acceptable way to evaluate a student's performance. Engineering graphics educators will have to learn new ways of assessing performance by examining the electronic files of students. If we do not find ways to design new activities and new ways evaluating performance, we risk losing our respected place within engineering design.

\section{Bibliography}

1. Branoff, T. J., Hartman, N. W. \& Wiebe, E. N. (2002). Three-dimensional solid modeling in an introductory engineering graphics course: Re-examining the curriculum. Engineering Design Graphics Journal, 66 (1), 5-10.

2. Baxter, D. H. (2002). Evaluating student performance in a freshman graphics course to provide early intervention for students with visualization and/or design intent difficulties. Paper presented at the 2002 Annual Conference of the American Society for Engineering Education, Montreal, Quebec, Canada, June16-19, 2002.

3. Wiebe, E. N., Branoff, T. J. \& Hartman, N. W. (2002). Teaching geometry through dynamic modeling in introductory engineering graphics. Paper presented at the $57^{\text {th }}$ Midyear Conference of the Engineering Design Graphics Division of the American Society for Engineering Education, Indianapolis, Indiana, October 27-30, 2002 .

4. Branoff, T. J., Hartman, N. W. \& Wiebe, E. N. (2002b). Constraint-based, solid modeling: What do employers want our students to know?. Paper presented at the 2002 Annual Conference of the American Society for Engineering Education, Montreal, Quebec, Canada, June16-19, 2002.

5. Baxter, D. H. (2002). Evaluating student performance in a freshman graphics course to provide early intervention for students with visualization and/or design intent difficulties. Paper presented at the 2002 Annual Conference of the American Society for Engineering Education, Montreal, Quebec, Canada, June16-19, 2002.

6. Baxter, D. H. (2002). Evaluating student performance in a freshman graphics course to provide early intervention for students with visualization and/or design intent difficulties. Paper presented at the 2002 Annual Conference of the American Society for Engineering Education, Montreal, Quebec, Canada, June16-19, 2002.

Proceedings of the 2003 American Society for Engineering Education Annual Conference \& Exposition. Copyright 2003, American Society for Engineering Education 


\section{Biography}

THEODORE J. BRANOFF, Ph.D.

Ted Branoff is an assistant professor of Graphic Communications at North Carolina State University and has been an ASEE member since 1986. He has taught courses in introductory engineering graphics, computer-aided design, descriptive geometry, and vocational education. Ted has a Bachelor of Science degree in Technical Education, a Master of Science in Occupational Education, and a Ph.D. in Curriculum and Instruction. His current academic interests include spatial visualization ability, geometric dimensioning and tolerancing, and graphics education.

ERIC N. WIEBE, Ph.D.

Dr. Wiebe is an Assistant Professor in the Graphic Communications Program at NC State University. He has authored or co-authored four texts on technical graphics and has been involved in Computer-Aided Design (CAD)/3D modeling development and use since 1986. During the past nine years, he has worked on the integration of scientific visualization concepts and techniques into both secondary and post-secondary education. Dr. Wiebe has been a member of the EDG Division of ASEE since 1989.

\section{NATHAN W. HARTMAN}

Nate Hartman is a doctoral student in Technology Education at North Carolina State University, where he is also a teaching assistant in the Graphic Communications program. Prior to attending NC State, Nate was a technical trainer for Rand Worldwide, where he instructed engineers and designers in the use of CAD and data management software. He holds a Bachelor of Science in Technical Graphics and Master of Science in Technology from Purdue University. 